\title{
The Synthesis of Agent Produced by Interaction of the Complex Trans-Dichlorodiamminplatinum(II) with Arabinogalactan and its Properties
}

\author{
Alexander K. Starkov, \\ Galina A. Kozuchovskaya and Nina I. Pavlenko* \\ Institute of Chemistry and Chemical Technology SB RAS \\ 50/24 Akademgorodok, Krasnoyarsk, 660036, Russia
}

Received 20.12.2015, received in revised form 13.01.2016, accepted 22.03.2016

The obtained new product of reaction of the complex trans-dichlorodiaminplatinum(II) with arabinogalactan was characterized by XRD, IR-spectroscopy, UF-spetrophotometry and thermogravimetry. The composition and structure of this product was studied. It has been shown that trans-dichlorodiaminplatinum(II) associated with arabinogalactan through-C-O-C-amino hydrogen of the original complex.

The synthesized product has the improved pharmacological properties being more soluble, less toxic and shows a greater anticancer activity as compared to cis-dichlorodiaminplatinum(II).

Keywords: complex compounds of platinum, synthesis, physicochemical properties, arabinoga-lactan, anticancer activity.

DOI: $10.17516 / 1998-2836-2016-9-1-42-48$.

(C) Siberian Federal University. All rights reserved

* Corresponding author E-mail address: kaz@icct.ru 


\title{
Получение препарата
}

\section{на основе взаимодействия соли}

\section{транс-дихлородиамминплатины(II)}

\section{с арабиногалактаном и его свойства}

\author{
А.К. Старков, Г.А. Кожуховская, Н.И. Павленко \\ Институт химии и химической технологии СО РАН \\ Россия, 660036, Красноярск, Академгородок, 50/24
}

\begin{abstract}
При взаимодействии комплекса транс-дихлородиамминплатины(II) с арабиногалактаном получен новый препарат, который охарактеризован методами РФА, ИК-спектроскопии, УФспектрофотометрии и термогравиметрии. Изучены состав и строение этого препарата. Показано, что транс-дихлородиамминплатины(II) удерживаются арабиногалактаном водородными связями, образованными эфирными группами, $-\mathrm{C}-\mathrm{O}-\mathrm{C}-\mathrm{NH}_{3}$-группами исходного комплекса. Получен препарат с новыми фармакологическими свойствами повышенной растворимостью, пониженной токсичностью и большей эффективностью по сравнению с иис-дихлородиамминплатиной(II).
\end{abstract}

Ключевые слова: комплексные соединения платины, синтез, физико-химические свойства, арабиногалактан, противоопухолевая активность.

\section{Введение}

Комплексное соединение цис-дихлородиамминплатины(II) является химиотерапевтическим препаратом и первым в классе противоопухолевых препаратов [1-5]. В отличие от цис-дихлородиамминплатины(II) считалось, что транс-дихлородиамминплатины(II) не обладает фармакологической эффективностью. Его низкая активность связана с различием кинетических характеристик при процессах акватации этого комплекса. Трансдихлородиамминплатины(II) токсичен и обладает малой растворимостью [6]. Для преодоления данных проблем был получен препарат на основе взаимодействия комплекса транс-дихлородиамминплатины(II) с арабиногалактаном. Арабиногалактан содержит остатки арабинозы и галактозы, с помощью которых он способен взаимодействовать с асциалогликопротеиновым рецептором [7]. Благодаря этому свойству указанный полисахарид может применяться для доставки внутрь клетки веществ, не способных к самостоятельному проникновению через мембрану. Это позволяет использовать его в качестве лиганда при взаимодействии с транс-дихлородиамминплатиной(II). В результате получается препарат с новыми фармакологическими свойствами, такими как повышенная растворимость, пониженная токсичность, большая эффективность.

Данная статья посвящена синтезу нового препарата на основе взаимодействия трансдихлородиамминплатины(II) с арабиногалактаном. Проведено физико-химическое исследование этого препарата и представлены его медико-терапевтические свойства. 


\section{Экспериментальная часть}

Комплексное соединение транс-дихлородиамминплатины(II) получено по методике [8]. Арабиногалактан с молекулярной массой 15 кД, получаемый по способу [9], имеет чистоту не менее $99 \%$. Продукт взаимодействия комплексного соединения трансдихлородиамминплатины(II) с арабиногалактаном получен по следующей методике.

К 30 мл водного раствора соли транс-дихлородиамминплатины(II) с концентрацией 0,05 ммоль добавляли 1,50 мл 50 \% раствора арабиногалактана при интенсивном перемешивании. Смесь нагревали на водяной бане в течение 90 мин и фильтровали через бумажный фильтр синяя лента. Выделение препарата проводили высаживанием в спирте. Выход препарата составил 88 \% с содержанием платины $1,06 \%$.

Порошковые рентгенограммы регистрировали на дифрактометре X pert Pro (PANalytical, Нидерланды) с геометрией по Бреггу-Брентано, оснащенном полупроводниковым детектором PIXel с графитовым монохроматором. Использовали $\mathrm{CuK \alpha}$-излучение. Интервал съемки от 10 до $90^{\circ} \mathrm{c}$ шагом $0,026^{0}$.

ИК-спектры соединений регистрировали на ИК- Фурье-спектрометре Vector 22, (Bruker Германия) в области 4000-400 см-1. Образцы для съемки спектров поглощения готовили в матрице бромистого калия с навеской исследуемого образца 3,0 мг, навеска матрицы постоянна и равна 1 г. Условия приготовления образцов (время перемешивания с бромистым калием, давление прессования, время вакуумирования) одинаковы, толщины полученных таблеток постоянны (в пределах величины $(1,150 \pm 0,005)$ мм). Обработка спектральной информации осуществлялась с применением пакета программ OPUS 3, версия 2.2. Собственное поглощение таблетки бромистого калия перед обработкой спектров образцов вычтено. Исследуемые образцы представляют собой смеси свободного арабиногалактана и комплекса арабиногалактана с солями платины. Для исключения полос поглощения свободного арабиногалактана в анализируемой смеси получены дифференциальные спектры с использованием подпрограммы OPUS 3 Spectrum Subtraction.

Электронные спектры поглощения снимали на спектрофотометре Specord UV-VIS. Применяли процедуру сканирования спектров в области $28000-46000 \mathrm{~cm}^{-1}$.

Термограммы соединений получали на приборе NET2SCH STA 449 C. Нагревание проводили в интервале температур от 20 до $1000^{\circ} \mathrm{C}$ со скоростью $10^{\circ} \mathrm{C}$ в минуту. Масса навесок комплексов составляла 10 мг.

\section{Результаты и их обсуждение}

Были проведены рентгенографические исследования полученного препарата, механической смеси исходного комплекса транс-дихлородиамминплатины(II) и арабиногалактана. Показано, что арабиногалактан рентгеноаморфен. В механической смеси трансдихлородиамминплатины(II) и арабиногалактана проявляется кристаллическая фаза транс-дихлородиамминплатины(II). В рентгенограмме продукта с содержанием платины 1,06 \% исходной кристаллической фазы транс-дихлородиамминплатины(II) не наблюдается. Этот результат свидетельствует о том, что комплексное соединение транс-дихлородиамминплатины(II) связано с арабиногалактаном, образуя новый продукт. Аналогичные результаты были получены при исследовании препарата цис-дихлородиамминплатины(II) с арабиногалактаном [10]. 
Согласно ИК-спектроскопическим исследованиям полосы валентных колебаний $v_{\mathrm{NH}}$ на ИК-спектрах для транс-дихлородиамминплатины(II) располагаются на $v_{\mathrm{NH}}=3287 \mathrm{~cm}^{-1}$ и 3193 $\mathrm{cm}^{-1}$. Для синтезированного препарата они сдвинуты в низкочастотную область до значений $v_{\mathrm{NH}}=3255 \mathrm{~cm}^{-1}$ и $3183 \mathrm{~cm}^{-1}$, характерных для аминовых комплексов платины(II) [11]. Полосы поглощения, обусловленные колебаниями связи -C - О - С - для арабиногалактана - 1078 и $1042 \mathrm{~cm}^{-1}$, для полученного препарата смещаются на 1061 и $1006 \mathrm{~cm}^{-1}$ соответственно [12]. Эти результаты свидетельствуют о наличии в образовавшемся продукте связи исходного комплекса с арабиногалактаном.

Результаты УФ-спектрофотометрического исследования растворов комплексного соединения транс-дихлородиамминплатины(II), полученного препарата и арабиногалактана приведены в табл. 1. Из этих данных видно, что коэффициенты экстинции для трансдихлородиамминплатины(II) и арабиногалактана намного ниже, чем для полученного препарата. Это является косвенным доказательством отсутствия в препарате исходных веществ.

Термограммы арабиногалактана и полученного продукта приведены на рис. 1 и 2. На кривой ДСК для арабиногалактана имеется два экзоэффекта при температуре 358 и $495{ }^{\circ} \mathrm{C}$ (рис. 1), на кривой ДСК для полученного препарата при более низких температурах наблюдаютя три экзоэффекта при 320,350 и $371{ }^{\circ} \mathrm{C}$ (рис. 2). Эти факты свидетельствуют о том, что взаимодействие транс-дихлородиамминплатины(II) с арабиногалактаном приводит к образованию нового препарата. На кривой ДТГ имеются четыре эндоэффекта при температурах 92, 180, 265 и $465{ }^{\circ} \mathrm{C}$ (рис. 1). А для полученного препарата обнаружено три эндоэффекта при температурах 243, 350 и $368^{\circ} \mathrm{C}$ (рис. 2). Первый эндоэффект связан с потерей кристаллической воды, второй -

Таблица 1. Молярные коэффициенты поглощения $\varepsilon\left(\right.$ моль $\left.^{-1} \cdot \int^{\cdot} \mathrm{cm}^{-1}\right)$ транс-[ $\left.\mathrm{Pt}\left(\mathrm{NH}_{3}\right)_{2} \mathrm{Cl}_{2}\right]$, арабиногалактана и препарата, полученного при взаимодействии транс-[ $\left.\mathrm{Pt}\left(\mathrm{NH}_{3}\right)_{2} \mathrm{Cl}_{2}\right]$ с арабиногалактаном

\begin{tabular}{|c|c|c|c|}
\hline $\begin{array}{l}v \cdot 10^{3}, \\
\mathrm{~cm}^{-1}\end{array}$ & $\begin{array}{c}\varepsilon_{\text {транс-[Pt(NH3)2C12] }}, \\
\text { моль }^{-1} \cdot \pi \cdot \mathrm{CM}^{-1}\end{array}$ & $\begin{array}{l}\mathcal{E}_{\text {арабиногалактана }} \\
\text { мОль }^{-1} \cdot \int^{-} \cdot \mathbf{C M}^{-1}\end{array}$ & $\begin{array}{c}\varepsilon_{\text {препарата }} \\
\text { моль }^{-1} \cdot \pi \cdot \mathbf{C M}^{-1}\end{array}$ \\
\hline 42 & 106 & 8676 & 13939 \\
\hline 41 & 98 & 5882 & 13333 \\
\hline 40 & 48 & 4853 & 12273 \\
\hline 39 & 54 & 4559 & 10909 \\
\hline 38 & 70 & 4853 & 9848 \\
\hline 37 & 78 & 5735 & 9697 \\
\hline 36 & 74 & 7206 & 9697 \\
\hline 35 & 59 & 8382 & 9697 \\
\hline 34 & 52 & 7941 & 9848 \\
\hline 33 & 55 & 6765 & 10151 \\
\hline 32 & 63 & 5000 & 10151 \\
\hline 31 & 59 & 4191 & 10151 \\
\hline 30 & 39 & 3676 & 8787 \\
\hline 29 & 24 & 3182 & 7272 \\
\hline 28 & 20 & 2424 & 6364 \\
\hline
\end{tabular}




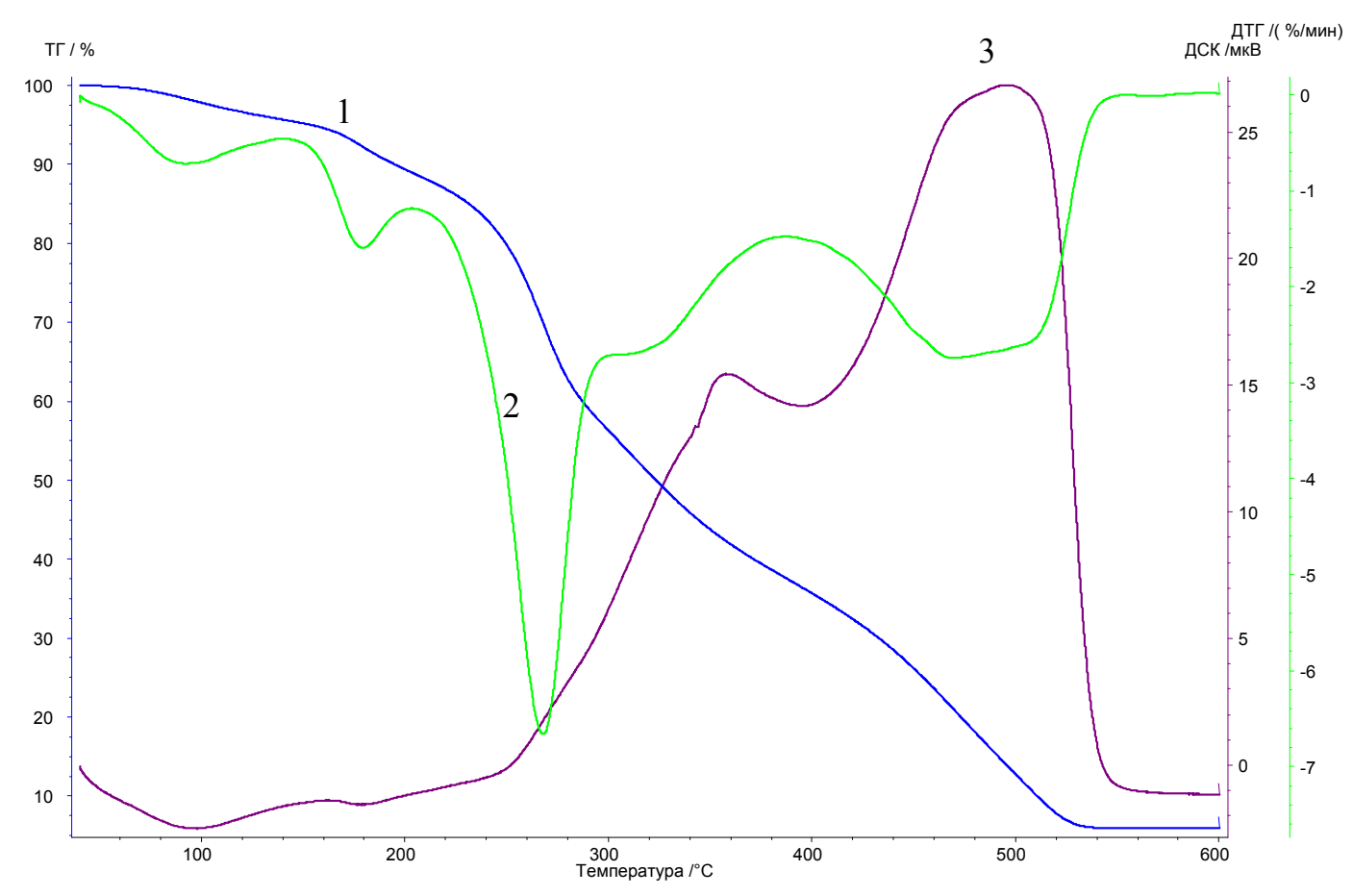

Рис. 1. Термограмма арабиногалактана: 1 - ТГ; 2 - ДТГ; 3 - ДСК

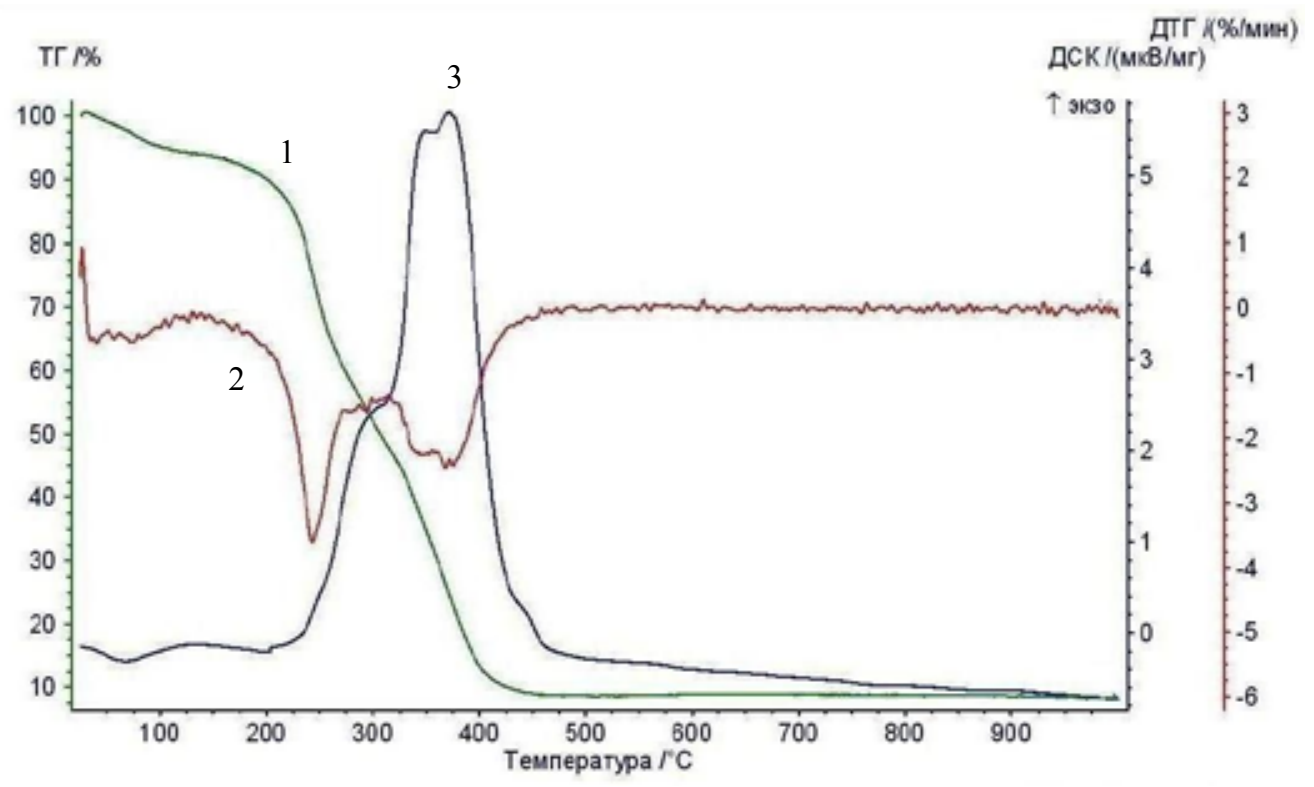

Рис. 2. Термограмма продукта: 1 - ТГ; 2 - ДТГ; 3 - ДСК 
с потерей воды от фрагмента арабинозы арабиногалактана (по потере массы) (рис. 1). Эндоэффект при температуре $265^{\circ} \mathrm{C}$ для арабиногалактана и $243{ }^{\circ} \mathrm{C}$ для препарата, по-видимому, связан с распадом арабиногалактана. При температуре 350 и $368{ }^{\circ} \mathrm{C}$ наблюдаемый экзоэффект для препарата, вероятно, связан с распадом препарата, содержащего комплекс трансдихлородиамминплатины(II), в то время как на кривой ДТГ для арабиногалактана этот эффект отсутствует. Эндоэффект при температуре $465^{\circ} \mathrm{C}$ для арабиногалактана и $368^{\circ} \mathrm{C}$ для препарата указывает на дальнейшее разложение, которое заканчивается при температуре $550{ }^{\circ} \mathrm{C}$ для арабиногалактана и $490{ }^{\circ} \mathrm{C}$ для препарата до металлической платины, согласно данным кривых ТГ для арабиногалактана и препарата, (рис. 1 и 2).

\section{Заключение}

На основании полученных физико-химических данных можно сделать вывод, что взаимодействие комплекса транс-дихлородиамминплатины(II) с арабиногалактаном приводит к образованию продукта, в котором предположительно комплекс трансдихлородиамминплатины(II) связан с арабиногалактаном по связи - C - O - C - водородом $\mathrm{NH}_{3}$-группы исходного комплекса. Количество комплекса платины(II) в продукте согласно анализу на платину составляет $1,6 \%$.

Исследование противоопухолевого действия синтезированного препарата на рост асцидных клеток карциномы Эрлиха показало, что он обладает способностью тормозить рост опухолевых клеток, не оказывая токсического действия на организм.

Растворимость его в 20 раз выше растворимости исходного транс-дихлородиамминплатины(II). Эффективность препарата не ниже чем эффективность цис-дихлородиамминплатины(II). Причем содержание комплекса в препарате намного меньше [13].

Работа выполнена с использованием оборудования ЦКП Красноярского научного центра Сибирского отделения Российской академии наук.

\section{Список литературы}

1. Rosenberg W.,Van Camp L., Mansuor V.N Platinum compounds: A new class of potent antitumor agents. Nature. 1969. V. 222. P. 385-386.

2. Pil P., Lippard S.J., Bertino J.R. Leaning from the past teaching old platinum compounds new tricks. Encyclopedia of Cancer. Education Academic Press: San Diego. C.A. 1997. V. 1. P. 392-410.

3. Boulikas T., Vougiouka M. Recent clinical trials using cisplatin, carboplatin and their combination chemotherapy drugs. Oncology Reports. 2004. V.11. P. 559.

4. Cleare M.J., Hoeschele J.D. Studies on the antitumor cytivity of group VIII transition metal complexes Part 1 Platinum(II) complexes. Bioinorganic chemistry.1973. V.2. P. 187-210.

5. Cleare M.J. Transition metal complexes in cancer chemotherapy. Coordination chemistry Reviews.1974. V.12. P. 349-405.

6. Гринберг А.А., Доброборская А.И. Растворимость изомерных платодиамминов в воде. Журнал неорганической химии. 1967. T.12. № 1. С. 276-277. [Grinberg A.A.,Dobrovolskaya A.I. Solubility in water isomeric platodiamminov. Russian Journal of Inorganic Chemistry 1967. Vol.12. № 1. P.276-277.(In Russ.)] 
7. Grieshop C.M., Flickiger E.A., Fahey G.C. Oral administration of arabinogalactan affects immune status and fecal microbial populatione delivery. Journal of Nutrition 2002. V.132. № 3. P. 478-485.

8. Синтезы комплексных соединений металлов платиновой группы. Справочник. Под ред. И.И. Черняева. М.: Наука, 1964.340 с. С.22. [Synthesis of complex compounds of platinum group metals. Handbook. Under Ed. Chernyaeva I.I. Moscow: Nauka, 1964. 340 p. (In Russ.)]

9. Патент 2143437 РФ. Бабкин В.А., Остроухова Л.А., Медведева С.А., Бабкин Д.В., Малков Ю.А., Александрова Г.П., Антонов Л.Н.. Способ получения высокочистого арабиногалактана., Опубл. 27.12.1999. [Patent 2143437 RU. Babkin V.A., Ostrouchova L.A., Medvedeva S.A., Babkin D.V., Malkov U.A., Aleksandrova G.P., Antonov L.N. A method of producing a high clean arabinogalactan. Publ. Date 27.12.1999 (In Russ.)]

10. Старков А.К., Кожуховская Г.А., Павленко Н.И. Продукт взаимодействия комплекса цис-дихлородиамминплатины(II) с матрицей-носителем арабиногалактаном и его свойства. Журнал СФУ. Химия. 2015. Т. 8. № 2. C.269-276. [Starkov A.K., Kozuchovskaya G.A., Pavlenko N.I. The reaction product of the complex cis-dichlorodiammplatinum(II) with matrix carrier arabinogalactan and its properties. Journal of Siberian Federal University. Chemistry. 2015. Vol. 8. № 2. P. 269-276. (In Russ.)]

11. Желиговская Н.Н., Фатькин А.Ю. Исследование физико-химических свойств несимметричных цис-диамминдихлоро комплексов платины(II). Кординаџионная химия. 1986. Т. 12. № 8. C. 1127-1131. [Sheligovskaya N.N., Fatkin A.U. The study of physical-chemical properties of the asymmetrical diamminochloro complexes of platinum(II). Russian Journal of Coordination Chemistry 1986. Vol.12(8). P.1127-1131. (In Russ.)]

12. Кузнецова С.А., Михайлов А.Г., Скворцова Г.П., Александрова Н.В., Лебедева А.Г. Идентификация процессов водной экстракции арабиногалактана из древесины лиственницы. Химия растительного сырья. 2005. № 1. С. 53-58. [Kuznecova S.A., Michailov A.G.,Skvorcova G.P., Alexandrova N.B., Lebedeva A.G. The Identification process water extraction of arabinogalactan larch wood. Khimiia rastitel ’nogo Syr’ya 2005. № 1. P. 53-58. (In Russ.)]

13. Старков А.К., Замай Т.Н., Савченко А.А., Инжеваткин Е.В., Титова Н.М., Коловская О.С., Лузан Н.А., Силкин П.П., Кузнецова С.А. Противоопухолевый эффект комплекса арабиногалактана с платиной. Доклады Академии наук. 2016. T. 467. № 1. C.1-3 [Starkov A.K., Zamai T.N., Savchenko A.A., Inzhevatkin E.V., Titova N.M., Kolovskaya O.S., Lusan N.A., Silkin P.P., kuznecova S.A. The antitumor effect of complex arabinogalactan with platinum. Russian Journal Doklady Akademii Nauk 2016. Vol.467(1). P.1-3.(In Russ.)] 